\title{
BMJ Open A national cohort study evaluating infant and fetal mortality caused by birth defects in Korea
}

Hyun Sun Ko, ${ }^{1}$ Dong Joo Kim, ${ }^{2,3}$ Yoohyun Chung, ${ }^{1}$ Jeong Ha Wie, ${ }^{1}$ Sae Kyung Choi, ${ }^{1}$ In Yarg Park, ${ }^{1}$ Yong Gyu Park, ${ }^{4}$ Jong Chul Shin ${ }^{1}$
To cite: Ko HS, Kim DJ, Chung Y, et al. A national cohort study evaluating infant and fetal mortality caused by birth defects in Korea. BMJ Open 2017;7:e017963. doi:10.1136/ bmjopen-2017-017963

- Prepublication history and additional material for this paper are available online. To view these files, please visit the journal online (http://dx.doi. org/10.1136/bmjopen-2017017963).

HSK and DJK contributed equally.

Received 29 May 2017

Revised 4 October 2017

Accepted 5 October 2017

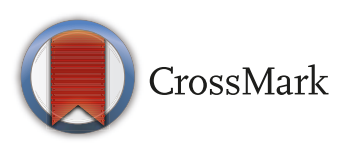

${ }^{1}$ Department of Obstetrics and Gynecology, College of Medicine, The Catholic University of Korea, Seoul, Republic of Korea

${ }^{2}$ Department of Obstetrics and Gynecology, Graduate School,

The Catholic University of Korea, Seoul, Republic of Korea

${ }^{3}$ Department of Obstetrics and Gynecology, St Mary's Women's Hospital, Suwon, Republic of Korea

${ }^{4}$ Department of Biostatistics College of Medicine, The Catholic University of Korea, Seoul, Republic of Korea

Correspondence to Dr Jong Chul Shin; jcshin@catholic.ac.kr

\section{ABSTRACT}

Objective To analyse the prevalence of fetal and infant deaths due to birth defects in Korea and those trends according to maternal age.

Design Retrospective national cohort study

Setting Korean Vital Statistics database of the Korean Statistical Information Service, between 2009 and 2015. Participants 2176 infant deaths and 4343 fetal deaths caused by birth defects, among 3181145 total live births and 43385 fetal deaths during the study periods.

Methods Infant and fetal mortality rates (IMRs and FMRs) by birth defects, from deaths caused by birth defects, were analysed. They were compared, according to maternal age groups: (I) '10-19 years'; (II) '20-29years'; (III) '3034 years'; (IV) '35-39years'; and (V) '40-55 years'. Main outcome measures IMRs and FMRs by birth defects and comparison according to maternal age group. Results IMRs and FMRs by birth defects were 6.84 per 10000 live births and 13.47 per 10000 total births. The most common causes of infant deaths and fetal deaths by birth defect were anomaly of the circulatory system (51.1\%, IMR 3.5) and chromosomal abnormality (33.1\%, FMR 4.46), respectively. Among groups by maternal age, FMRs by birth defects were significantly higher in groups I and V compared with group III (OR 6.59, $95 \% \mathrm{Cl} 3.49$ to 12.43 ; and $\mathrm{OR} 3.46,95 \% \mathrm{Cl} 1.77$ to 6.78 , respectively). IMR and FMR by nervous system anomaly were significantly higher in group I at $3.63(\mathrm{OR} 2.0,95 \% \mathrm{Cl}$ 1.97 to 2.03 ) and 29.84 (OR $15.04,95 \% \mathrm{Cl} 3.59$ to 62.96 ) compared with 0.32 and 1.97 in group III.

Conclusion FMRs by birth defects were the highest in the extreme maternal age groups. Severe anomalies, except for chromosomal abnormality, were most prevalent in teenage pregnancies.

\section{INTRODUCTION}

Birth defects (structural abnormalities, sensory changes, chromosomal abnormalities, metabolic abnormalities, and neurodevelopmental defects) are present in approximately $2-3 \%$ of all births. ${ }^{1-3}$ Severe birth defects account for $20-25 \%$ of perinatal mortality and they are the leading cause of infant mortality, abortion, and stillbirth. ${ }^{2-5}$ During the last decade, screening tests and ultrasonography during pregnancy have been

\section{Strengths and limitations of this study}

- This study is the first to report infant and fetal mortalities caused by birth defects in Korea, from the National Vital Statistics.

- This study compared the infant and fetal mortalities caused by birth defects, according to maternal age group, which showed a higher prevalence of them in teenage pregnancies.

- A limitation of this study is that the causes of fetal/ infant deaths were mostly diagnosed clinically without autopsy and there were no available data on spontaneous or induced abortion in fetal deaths.

- A further limitation is that the study does not show the present prevalence of birth defects in live births.

developed to detect birth defects. However, the aetiologies of $60-70 \%$ of birth defects remain unknown.

In developed countries, surveillance systems for birth defects have been developed to collect data on major structural birth defects and chromosomal abnormalities. ${ }^{6-8}$ A European registry reported that the total and live birth prevalence of trisomies 21, 18 and 13 increased between 1990 and 2009, and were mainly associated with increasing maternal age. $^{9}$

While the number of live births in Korea has decreased, maternal age has increased. ${ }^{1011}$ The prevalence of birth defects in Korean live births has been reported before, using the data based on the National Health Insurance Corporation and medical institutes across the country. ${ }^{12} 13$ However, it is important to include stillbirths in addition to live births to account for all pregnancies with birth defects. Although it is hard to include spontaneous abortion in the early stage of pregnancy, the investigation of fetal death related to birth defects can be useful for estimating the prevalence of birth defects. In addition, the investigation of infant deaths related to birth defects can provide valuable information for counselling parents, antenatally and postnatally. 
The aim of this study was to analyse the prevalence of fetal and infant deaths associated with birth defects, which are fetal/infant mortality rates (FMR/IMR) by birth defect, and evaluate the changes in these prevalence rates, according to maternal age.

\section{METHODS}

This national cohort study was conducted by utilising de-identified data about fetal deaths, infant deaths, and live births between 2009 and 2015 from 'Korean Vital Statistics' of the Korean Statistical Information Service. ${ }^{10}$ Korean Vital Statistics is a nationwide database developed to monitor and understand the rates of birth, death, marriage, and divorce in Korea. Data from Korean Vital Statistics are released monthly and annually via a press release, on its website (http://kosis.kr), and in online publications, such as 'Annual Report on Vital Statistics.' Since 2007, surveys and statistical analysis methods for infant and maternal deaths have been revised and complemented ${ }^{14}$ to develop into a method for calculating more concrete, accurate numbers for fetal, infant, and maternal mortality rates in Korea. In summary, revision and supplementation of the statistics for fetal, infant and maternal deaths have been performed and validated by a combination of official death registry data for vital statistics, survey data of a public health centre or medical institution, the medical insurance claims database of the National Health Insurance Corporation on medical institutes across the country, and data from cremation reports. Because national data about fetal death have been included since 2009, the cohort for this study was derived from data obtained between 2009 and 2015. However, data did not include information on whether the cause of death was proven by autopsy. From fetal and infant death data, deaths recorded as 'a death caused by birth defect' were included in fetal and infant deaths associated with birth defects. Fetal death was defined as an intrauterine fetal death occurring after 16 weeks of gestational age and before the start of delivery or those occurring during labour. Infant death was defined as a death occurring within the first year of life.

Birth defects were categorised by birth defect group (the system affected) and subtype (individual disease) according to the 10th revision of the International Classification of Diseases (ICD-10) and were investigated by including major groups of birth defects managed by the European Association of Congenital Anomalies (EUROCAT), the International Clearinghouse for Birth Defects Surveillance and Research (ICBDSR), and the National Birth Defects Prevention Network (NBDPN). Deaths caused by disease code ' $Q$ ' representing congenital disease were defined as fetal and infant deaths related to birth defects. According to the above standards, 2176 infant deaths and 4343 fetal deaths were caused by birth defects. This study calculated IMR by birth defects by dividing the number of infant deaths related to birth defects by the total number of live births. It was presented as the number per 10000 live births as a standard. FMR by birth defects was calculated by dividing the number of fetal deaths related to birth defects by the total number of live births and fetal deaths, which presented as the number per 10000 total births. Maternal age groups were divided to the following five groups: (I) '10-19years'; (II) '20-29 years'; (III) '30-34years'; (IV) '35-39years'; and (V) '40-55 years'. IMRs and FMRs by birth defects in group III were used as control for comparison with IMRs/ FMRs of the other groups. For chromosomal abnormalities, comparison was also performed between group II and the other groups.

\section{STATISTICAL ANALYSIS}

Statistical calculations were performed using SPSS version 24.0 (SPSS Inc, Chicago, IL, USA), including means, proportions, odds ratio (OR), and 95\% confidence intervals $(95 \% \mathrm{CI}) \cdot \chi^{2}$ tests were performed to compare proportions of independent variables and t-tests were performed to compare means. One decimal place was marked up in the presentation of maternal ages and gestational ages. Statistical significance was considered at $\mathrm{P}<0.05$ or if the $95 \% \mathrm{CI}$ of the OR did not include 1 .

\section{ETHICS STATEMENT}

The study protocol was approved by the Institutional Review Board of the Catholic University of Korea (KC17ZESI0409). Informed consent was waived by the board.

\section{RESULTS \\ Baseline characteristics}

The total number of live births and fetal deaths in Korea from 2009 to 2015 were 3181145 and 43 385, respectively. Among 9563 infant deaths during the 7 years, the number of infant deaths related to birth defects was 2176, accounting for $22.8 \%$ of all infant deaths. The number of fetal deaths related to birth defects was 4343 , accounting for $10.0 \%$ of all fetal deaths. Baseline demographic characteristics are summarised in table 1 .

\section{IMRs by birth defect groups and subtypes}

IMR by total birth defects was 6.84 per 10000 live births (table 2). Anomaly of the circulatory system was the most common cause of infant deaths related to birth defects, accounting for $51.1 \%$ of all infant deaths. Its IMR was 3.5 per 10000 live births. The next most common defects in infant deaths were chromosomal abnormality $(0.69$ per 10000 live births, 10.1\%) and musculoskeletal system anomalies (0.65 per 10000 live births, 9.6\%). Among subtypes of birth defects, congenital diaphragmatic hernia $(\mathrm{CDH})$ showed the highest IMR at 0.43 per 10000 live births (online supplementary material). Among specified anomalies, lethal birth defects with the next highest IMRs were tetralogy of Fallot (ToF) and hypoplastic left 
Table 1 Demographic characteristics of total live births, total fetal deaths, total infant deaths, and fetal/infant deaths related to birth defects

\begin{tabular}{llllll}
\hline & Total live births & Total fetal deaths & $\begin{array}{l}\text { Total infant } \\
\text { deaths }\end{array}$ & $\begin{array}{l}\text { Infant deaths by } \\
\text { birth defects }\end{array}$ & $\begin{array}{l}\text { Fetal deaths by } \\
\text { birth defects }\end{array}$ \\
\cline { 2 - 6 } Parameters & $\mathbf{n = 3 , 1 8 1 , 1 4 5}$ & $\mathbf{n = 4 3 3 8 5}$ & $\mathbf{n = 9 5 6 3}$ & $\mathbf{n = 2 1 7 6}$ & $\mathbf{n = 4 3 4 3}$ \\
\hline Maternal age (years) & $31.9 \pm 26.7$ & $30.7 \pm 6.2$ & $31.6 \pm 5.0$ & $31.7 \pm 4.9$ & $21.2 \pm 4.4$ \\
Gestational age (weeks) & $38.6 \pm 2.3$ & $20.1 \pm 5.8$ & $32.2 \pm 6.6$ & $35.9 \pm 4.4$ & $31.8 \pm 5.6$ \\
Birth weight (kg) & $3.21 \pm 0.48$ & $0.69 \pm 0.78$ & $1.96 \pm 1.15$ & $2.47 \pm 0.87$ & $0.51 \pm 0.5$ \\
Multiple birth, $\mathrm{n}(\%)$ & $101797(3.2)$ & $3818(8.8)$ & $1492(15.6)$ & $196(9)$ & $200(4.6)$ \\
\hline
\end{tabular}

Data are presented as mean \pm SD deviation or no. (\%) unless otherwise specified.

heart syndrome (HLHS) (with IMRs of 0.28 and 0.27 per 10000 live births, respectively). Among chromosomal abnormalities, Down syndrome was the most common chromosomal abnormality with IMR of 0.27 per 10000 live births (table 3).

\section{FMRs by birth defect groups and subtypes}

FMR by total birth defects was 13.47 per 10000 total births (live births plus stillbirths) (table 2). The most common birth defect by group was chromosomal abnormality, accounting for $33.1 \%$ of fetal deaths related to birth defect, and its FMR was 4.46 per 10000 total births. The most common birth defect subtype in fetal deaths was Down syndrome with FMR of 1.78 per 10000 total births, followed by other chromosomal abnormalities, unspecified congenital heart malformation, and Edward syndrome, with FMR of 1.36, 0.93, and 0.82 per 10000 total births, respectively (table 3 and online supplementary material).

\section{IMRs and FMRs by birth defect groups, according to maternal age group}

In the analysis according to maternal age group, 2529 live births, 113 fetal deaths not related to birth defects, and 12 fetal deaths related to birth defects were excluded due to missing values of maternal age. In infant deaths related to birth defects, anomaly of the circulatory system was most common in all age groups (table 4 , figure 1 ). IMRs of chromosomal abnormality seemed to be increased in groups IV and V compared with group III. However, a statistically significant difference was only observed between group $\mathrm{V}$ and group III (OR 2.00, 95\% CI 1.97 to 2.03). The IMR of nervous system anomaly was significantly higher in the youngest maternal age group (group I, 10-19years), with 3.63 per 10000 live births (OR 2.0, 95\% CI 1.97 to 2.03), compared with group III (0.32 per 10000 live births). In fetal deaths related to birth defect, most FMRs by birth defect were highest in the youngest group, except for FMR by chromosomal abnormality which was significantly higher in group V compared with group III (OR 7.01, $95 \%$ CI 2.09 to 23.52) (table 5, figure 2). Compared with FMR of group II, FMRs of chromosomal abnormality were significantly higher in group IV and V (OR 5.00, 95\% CI 1.10 to 22.84 ; and OR $10.52,95 \%$ CI 2.47 to 44.88 , respectively). FMRs by total birth defects were significantly higher in group I and V compared with group III (OR $6.59,95 \%$ CI 3.49 to 12.43 ; and OR $3.46,95 \%$ CI 1.77 to 6.78 , respectively). Individually, FMRs for anomalies of the nervous system and cardiovascular system, and other and unspecified anomalies, were significantly higher in group I compared with group III (OR 15.04, 95\% CI 3.59 to 62.96 ; OR $10,95 \%$ CI 1.23 to 78.2 ; and OR $8.35,95 \%$ CI 2.52 to 27.67 , respectively)

\section{DISCUSSION}

It is important to know the types of severe birth defects which can lead to fetal and infant deaths and their prevalence. Previously, the prevalence of birth defects in Korea in live births in 2005 and 2006 was reported to be approximately $2.9 \%,{ }^{12}$ similar to those $(2-3 \%)$ of other studies. ${ }^{1-3}$ However, another study reported the prevalence of birth defects in Korea in 2009 and 2010 as 5.8\%. ${ }^{13}$ Although there might be methodological limitations and variations, the prenatal and postnatal detection rates of birth defects in live births seems to be increasing. In this study, $22.8 \%$ of infant deaths in Korea were related to birth defects. IMR and FMR caused by birth defects between 2009 and 2015 were 6.84 per 10000 live births and 13.47 per 10000 total births, respectively.

The most common birth defect group related to infant deaths was anomaly of the circulatory system. However, the most common birth defect subtype was CDH. Despite advances in prenatal diagnosis and neonatal intensive care, including extracorporeal membrane oxygenation and inhaled nitric oxide use, mortality rates due to $\mathrm{CDH}$ remain high, ranging from $50-70 \%$ with great variability between centres. ${ }^{15-17}$ The second most common birth defect in infant deaths was ToF. The 10-year survival rate of ToF has been reported to be approximately $95 \% .^{1819}$ When we consider the prevalence of ToF in live births in Korea with 4.1-4.2 per 10000 live births, ${ }^{12}{ }^{13}$ and the IMR from ToF with 0.28 per 10000 live births in this study, we can speculate that nationwide infant survival rates of ToF in Korea will be approximately $93.3 \%$, which is similar to survival rates in the other reports. ${ }^{1819}$

As expected, when IMRs and FMRs caused by birth defects were compared according to maternal age group, IMRs and FMRs due to chromosomal abnormality 


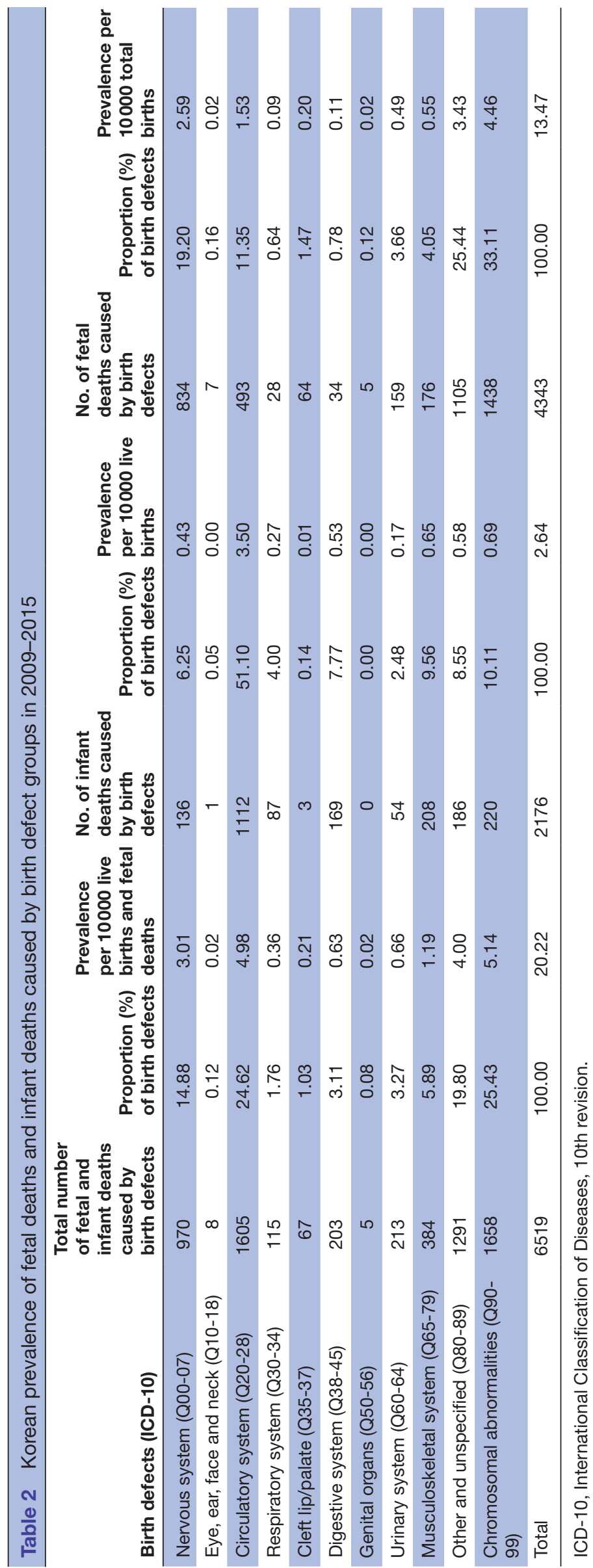




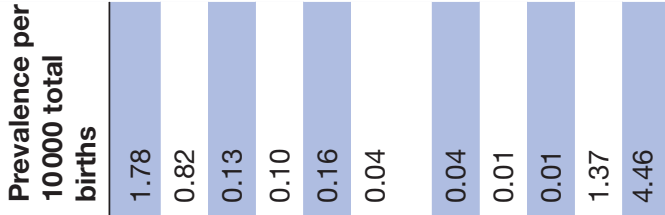
○造

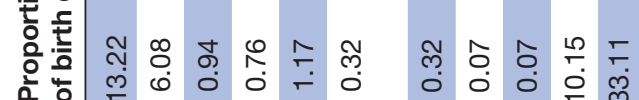

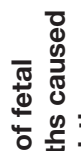

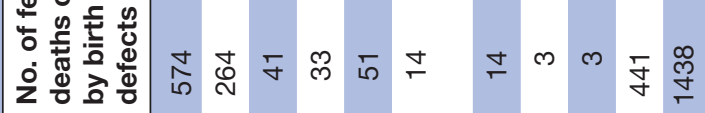
这

10

产竞言 ๖ํํㅇ

응 흉

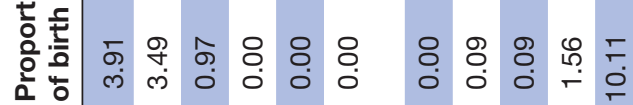

穿

车舟起

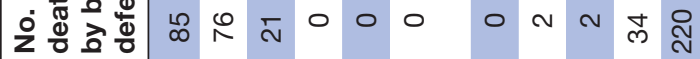
ळ

可

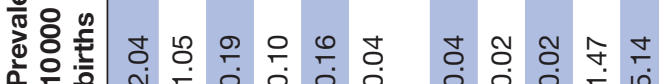

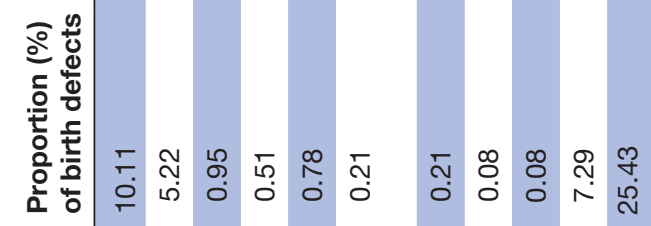

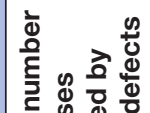

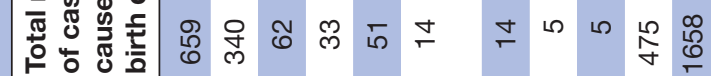

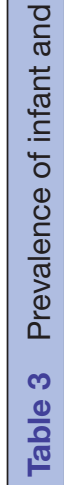

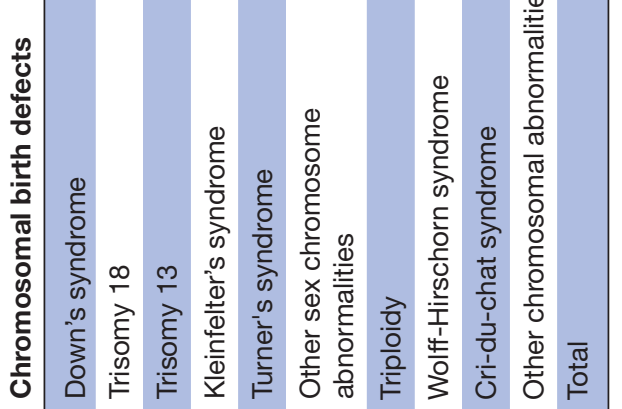

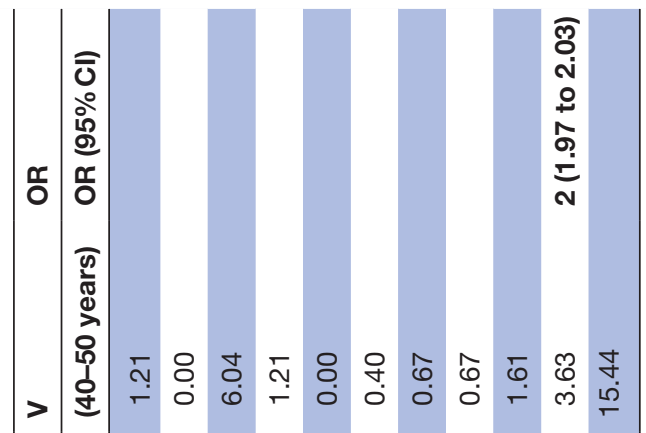

ชิ

(2)

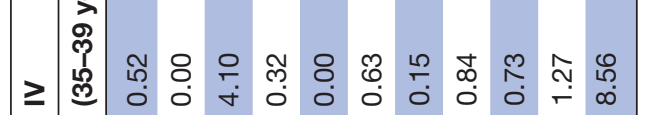

\)

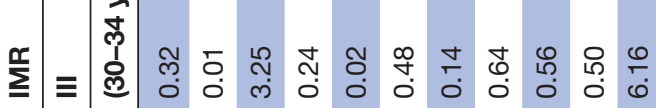

ธับ

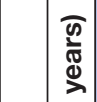

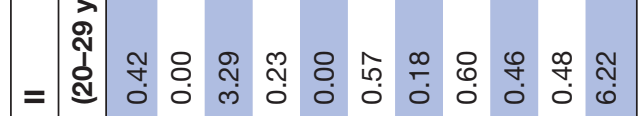

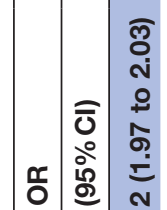

- 2

离

-

흔

\%

क

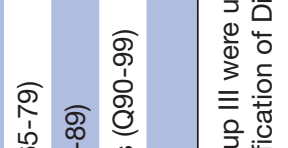

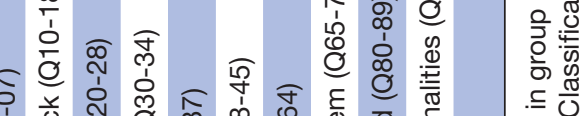

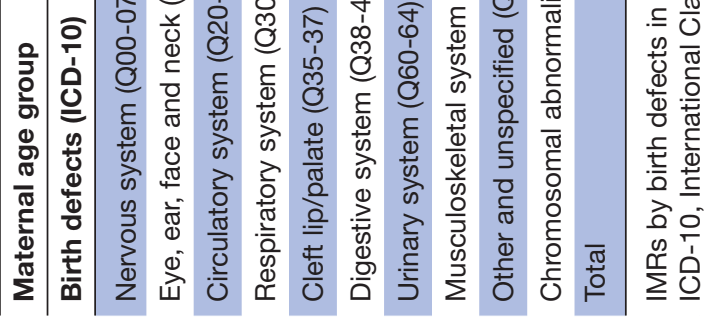

ज

Z

产

No 
Infant deaths per 10,000 live births

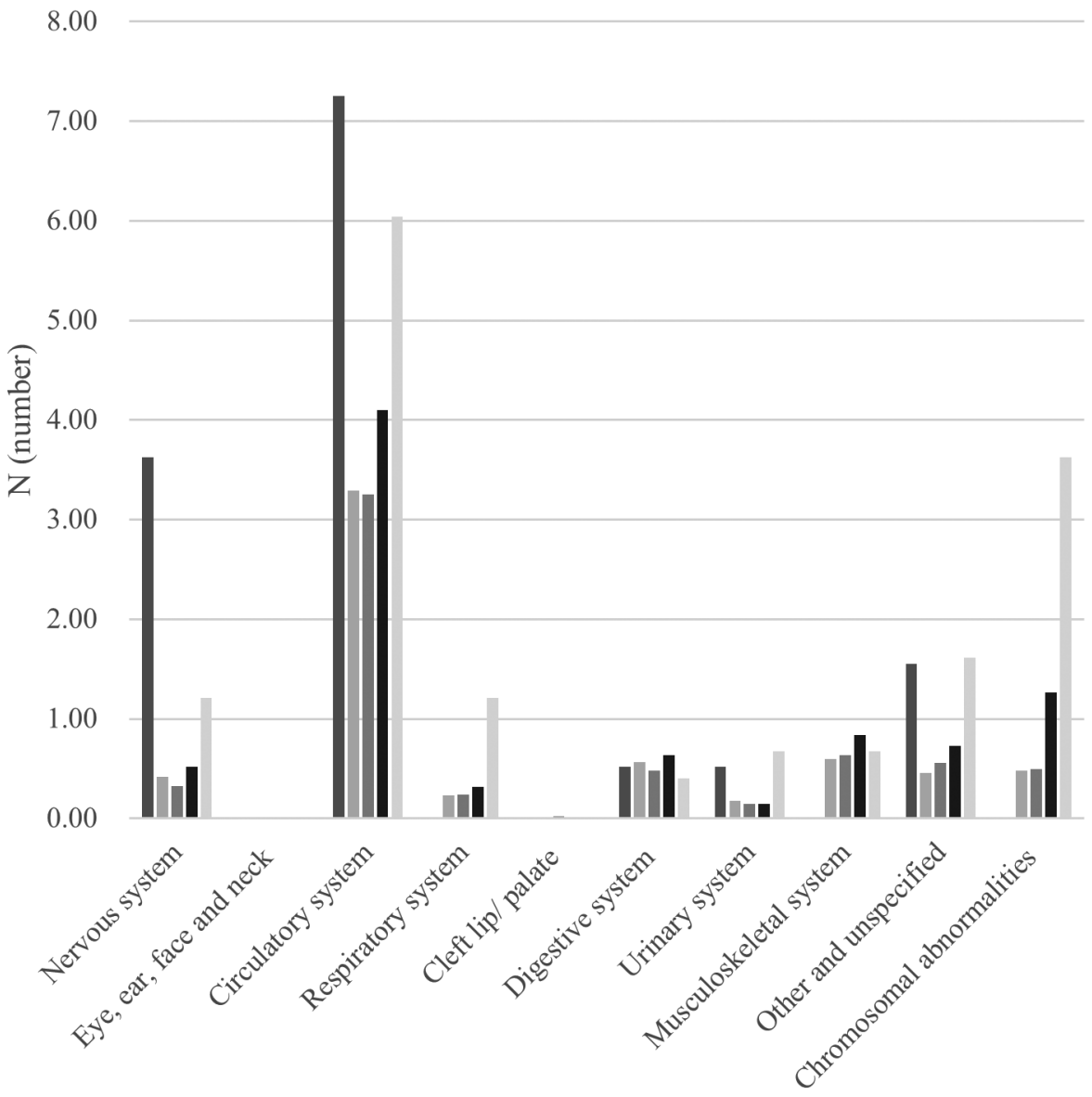

Birth defects in maternal age group

- I $\quad$ II $\square$ III $\square$ IV $\square \mathrm{V}$

Figure 1 Infant mortality caused by birth defects, according to maternal age group. Maternal age groups: (I) '10-19years'; (II) '20-29years'; (III) '30-34 years'; (IV) '35-39years'; and (V) '40-55 years'.

were higher in older maternal age groups (IV and V) compared with those in groups II or III. FMRs due to birth defects were significantly higher in groups I and V compared with those in group III (OR 6.59, 95\% CI 3.49 to 12.43 ; and OR $3.46,95 \%$ CI 1.77 to 6.78 , respectively). FMR was much higher in group I. In particular, IMR and FMR due to anomalies of the nervous system were significantly higher in group I compared with those in group III, indicating a higher prevalence of severe anomalies of the nervous system in teenage pregnancies. In North America, fortification of flour and grain products became mandatory in 1998. Following folic acid supplementation, the prevalence of spina bifida in infants in Canada fell by over $50 \%$ and that of other neural tube defects (NTDs) fell by approximately one-third. ${ }^{20}$ In addition, the registry of 'European surveillance of congenital anomalies' has concluded that mandatory folic acid fortification is needed because the prevalence of NTDs has not decreased in Europe despite longstanding recommendations aimed at promoting periconceptional folic acid supplementation. ${ }^{21}$ Results of a Cochrane database systematic review also showed a protective effect of daily folic acid supplementation in preventing NTDs compared with no intervention/placebo or vitamins and minerals without folic acid (risk ratio $0.31,95 \%$ CI 0.17 to 0.58 ; five studies; 6708 births; high quality evidence) ${ }^{22}$ Teenage pregnancies are more likely to be unplanned, with the pregnant individual exposed to alcohol, drugs, sexual abuse, and nutritional imbalance. When pregnancies are complicated by birth defects at a young age, they might result in termination of pregnancy (TOP) more readily. This study demonstrated increasing trends of IMRs and FMRs due to birth defects in the youngest and oldest maternal age groups. However, high IMRs and FMRs due to birth defects in the youngest age group were more pronounced except for chromosomal abnormalities. It is known that adolescent pregnancy is associated with higher risks of adverse neonatal outcomes, such as low birth weight and preterm delivery. ${ }^{23}$ In regard to birth defects, gastroschisis has been shown to be higher in young mothers. ${ }^{24}{ }^{25}$ However, there has been no other associations between young maternal age and any other 


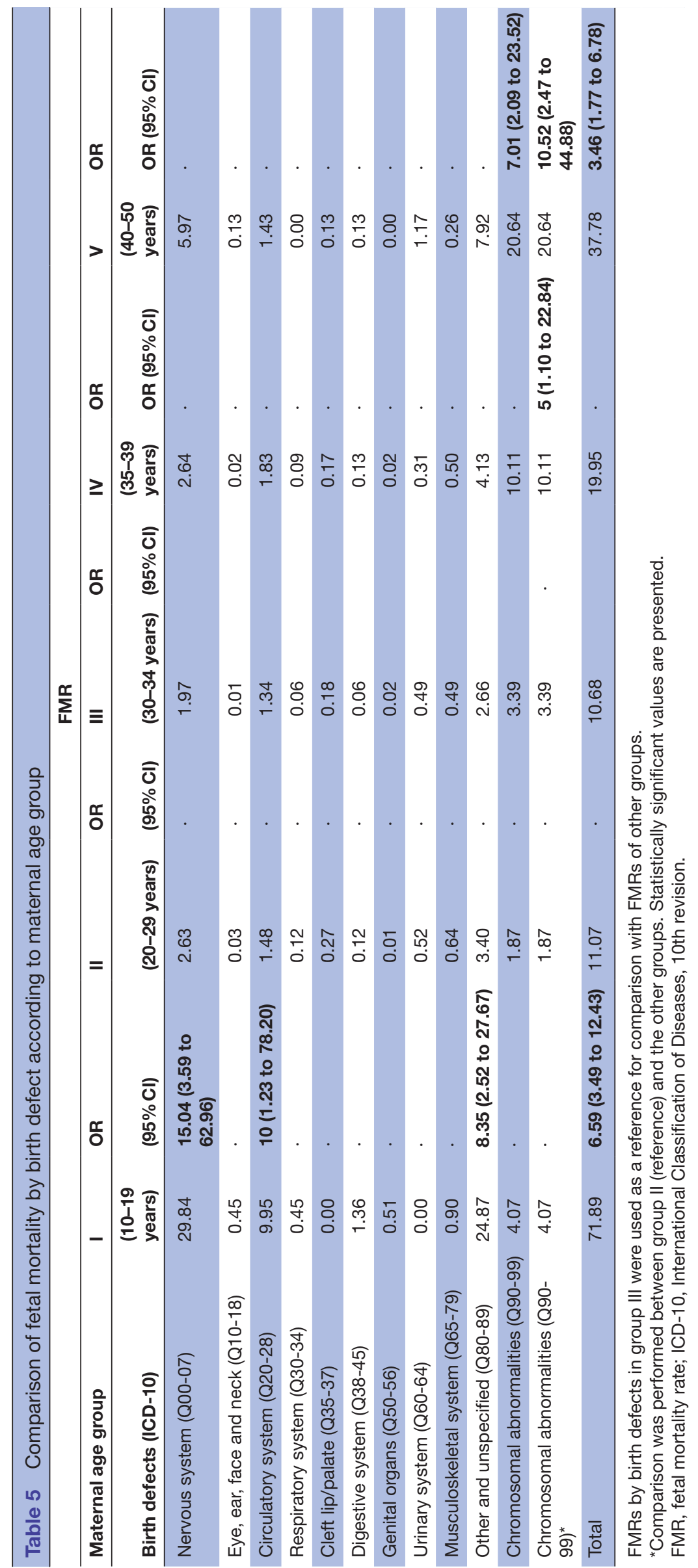

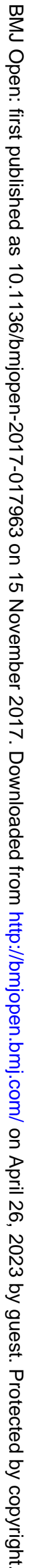


Fetal deaths per 10,000 total births

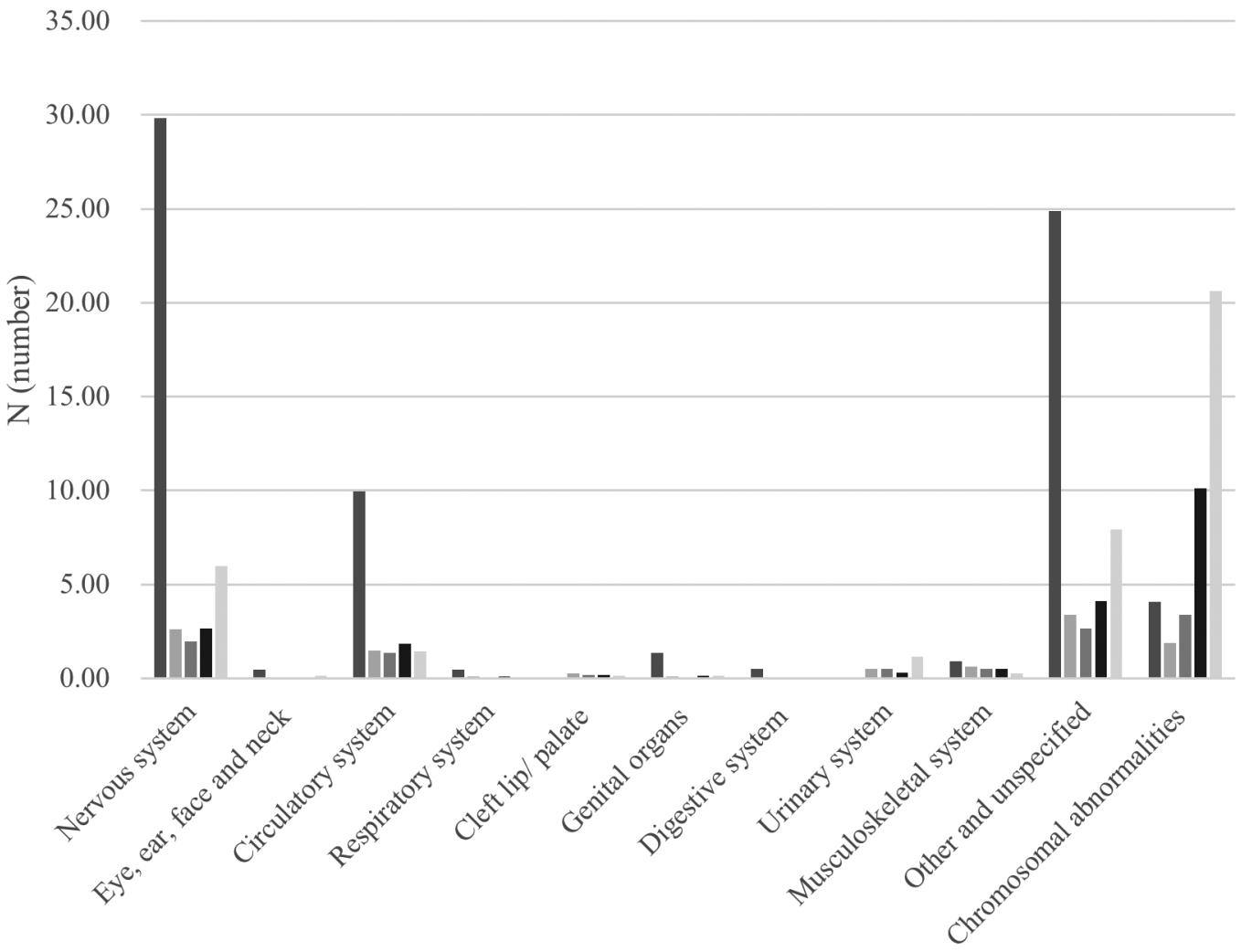

Birth defects in maternal age group

a $\quad$ II $\square$ III $\square$ IV $\square \mathrm{V}$

Figure 2 Fetal mortality caused by birth defects, according to maternal age group. Maternal age groups: (I) '10-19years'; (II) '20-29years'; (III) '30-34 years'; (IV) '35-39years'; and (V) '40-55years'.

birth defect, to our knowledge. Although it is unclear whether high IMRs and FMRs related to birth defects in the youngest maternal age group in this study are associated maternal age, or other social, nutritional, and environmental factors, further investigation might be needed in the future. In addition, mandatory folic acid supplementation in Korea might help reduce nervous system anomalies because the youngest age group is less likely to take periconceptional folic acid supplementation and the overall prevalence of spina bifida in Korea is showing a tendency to increase. ${ }^{13}$

In Europe, an increasing trend of trisomy 13, 18, and 21 between 1990 and 2009 has been reported. ${ }^{9}$ In Korea, most prenatal screening methods are available, such as the first trimester combined test, Quad screening, integrated, sequential test, and cell-free DNA screening. ${ }^{26}$ However, legally acceptable pregnancy termination is very restricted in Korea. The maternal and child health law only permits an abortion for one of the following reasons: if the pregnant woman or her spouse suffers from a eugenic or hereditary mental or physical disease specified by presidential decree; if the woman or her spouse suffers from a communicable disease specified by presidential decree; and if the pregnancy results from rape or incest or if continuation of the pregnancy is likely to jeopardise the mother's health. Therefore, it is almost impossible to estimate the proportions of TOP due to birth defects among fetal deaths. An international study has reported that the total mean prevalence of Down syndrome (in stillbirths, live births, and TOP) increased from 13.1 to 18.2/10 000 births between 1993 and 2004 with increasing maternal age. ${ }^{27}$ However, the total mean prevalence of Down syndrome live births remains stable at 8.3/10 000 births, balanced by a greater increase of TOP. ${ }^{27}$ Maternal age at conception has increased in Korea, although there are race/ethnic specific variations in birth defects. ${ }^{28}$ IMR and FMR from Down syndrome were 0.27 per 10000 live births and 1.78 per 10000 total births, respectively. When we assume the prevalence of Down syndrome as being 3.7-4.7 per 10000 live births from the previous studies in Korea, ${ }^{12}$ the infant survival rate of Down syndrome can be estimated at approximately $93.6 \%$. Based on the increased prevalence of Down syndrome in the international study, according to increasing maternal age, ${ }^{27}$ we can expect that TOP due to Down syndrome may also be considerable in Korea.

The first limitation of this study is that the cause of a fetal/infant death might be mostly decided upon by 
a clinician without an autopsy. Although most autopsies performed in the Republic of Korea are forensic autopsies, the autopsy rates for total mortality and unusual death in Korea were reported as $2.4 \%$ and $18.1 \%$, respectively, in 2015, which were very low. ${ }^{29}{ }^{30}$ This could be because the overwhelming majority of fetal losses are due to unspecified nervous, cardiovascular, and other system failures. Because one or two disease codes are registered as the main code in the death registry, multiple anomalies might have been included in one category. The second limitation of this study is that it does not show the present prevalence of birth defects in live births. Therefore, it is necessary to establish a comprehensive surveillance system with periodic production of data and monitoring to effectively prevent and manage birth defects. Lastly, this study did not include data on maternal nationality, paternal age, educational background, antenatal care, or parents' occupation due to high rates of missing values. However, this study is the first to report IMRs and FMRs caused by birth defects in Korea and different patterns according to maternal age group. Severe birth defects with high FMR swere found to be more common in extreme maternal age groups (the youngest and the oldest). With the exception of chromosomal abnormalities, most severe anomalies, especially those of the nervous and cardiovascular systems, were more common in teenage pregnancies.

As maternal age at conception is increasing in Korea and screening tools are developing, the prevalence and prenatal diagnosis of chromosomal abnormalities are likely to be increased. Multidisciplinary cooperation among government, politicians, clinicians, and non-governmental organisations is urgently required not only to increase the fertility rate, but also to increase the number of heathy pregnancies through the effective prevention and management of birth defects, especially for the extreme maternal age groups, and to support complicated pregnancies. Mandatory folic acid supplementation needs to be discussed and considered in Korea.

Contributors We confirm that all the authors have made substantive intellectual contributions to the paper; they understand their role in taking responsibility and being accountable for what is published. JCS conceptualised and reviewed the paper. HSK and DJK conceptualised the paper, gathered the results, analysed the data and wrote the article. YHC, JHW, SKC, and IYP analysed the data and reviewed the paper. YGP performed statistical analysis of the data.

Funding This study was supported by Research Fund of Seoul St Mary's Hospital, The Catholic University of Korea.

Competing interests None declared.

Ethics approval We obtained approval from the institutional review board of Catholic University of Korea (KC17ZESI0409).

Provenance and peer review Not commissioned; externally peer reviewed.

Data sharing statement № additional data are available.

Open Access This is an Open Access article distributed in accordance with the Creative Commons Attribution Non Commercial (CC BY-NC 4.0) license, which permits others to distribute, remix, adapt, build upon this work non-commercially, and license their derivative works on different terms, provided the original work is properly cited and the use is non-commercial. See: http://creativecommons.org/ licenses/by-nc/4.0/ (c) Article author(s) (or their employer(s) unless otherwise stated in the text of the article) 2017. All rights reserved. No commercial use is permitted unless otherwise expressly granted.

\section{REFERENCES}

1. Honein MA, Paulozzi LJ, Cragan JD, et al. Evaluation of selected characteristics of pregnancy drug registries. Teratology 1999;60:356-64.

2. Kalter $\mathrm{H}$, Warkany J. Congenital malformations (second of two parts). N Engl J Med 1983;308:491-7.

3. Kalter H, Warkany J. Medical progress. Congenital malformations: etiologic factors and their role in prevention (first of two parts). $N$ Engl J Med 1983;308:424-31.

4. Petrini J, Damus K, Russell R, et al. Contribution of birth defects to infant mortality in the United States. Teratology 2002;66(Suppl 1):S3-6.

5. Chung CS, Myrianthopoulos NC. Congenital anomalies: mortality and morbidity, burden and classification. Am J Med Genet 1987;27:505-23.

6. Centers for Disease Control and Prevention (CDC). Improved national prevalence estimates for 18 selected major birth defects-United States, 1999-2001. MMWR Morb Mortal Wkly Rep 2006;54:1301-5

7. Bower C, D'Antoine H, Stanley FJ. Neural tube defects in Australia: trends in encephaloceles and other neural tube defects before and after promotion of folic acid supplementation and voluntary food fortification. Birth Defects Res A Clin Mol Teratol 2009;85:269-73.

8. Khoshnood B, Greenlees R, Loane M, et al. on behalf of the EUROCAT Program Management Committee; EUROCAT working group. Paper 2: EUROCAT public health indicators for congenital anomalies in Europe. Birth Defects Res A Clin Mol Teratol 2011;91(Suppl 1):S16-22.

9. Loane M, Morris JK, Addor MC, et al. Twenty-year trends in the prevalence of Down syndrome and other trisomies in Europe: impact of maternal age and prenatal screening. Eur J Hum Genet 2013;21:27-33.

10. Korea S. Birth statistics in 2009-2015. Daejeon: Statistics Korea, 2009.

11. Choi SH, Park YS, Shim KS, et al. Recent trends in the incidence of multiple births and its consequences on perinatal problems in Korea. J Korean Med Sci 2010;25:1191-6.

12. Kim MA, Yee NH, Choi JS, et al. Prevalence of birth defects in Korean livebirths, 2005-2006. J Korean Med Sci 2012;27:1233-40.

13. Lamichhane DK, Leem JH, Park M, et al. Increased prevalence of some birth defects in Korea, 2009-2010. BMC Pregnancy Childbirth 2016;16:61.

14. Statistics Korea. Causes of death statistics. http://kostat.go.kr/ portal/eng/surveyOutline/5/1/index.static (accessed on 16 Aug 2017)

15. Park HW, Lee BS, Lim G, et al. A simplified formula using early blood gas analysis can predict survival outcomes and the requirements for extracorporeal membrane oxygenation in congenital diaphragmatic hernia. J Korean Med Sci 2013;28:924-8.

16. Campbell BT, Herbst KW, Briden KE, et al. Inhaled nitric oxide use in neonates with congenital diaphragmatic hernia. Pediatrics 2014;134:e420-6.

17. Lee JY, Jun JK, Lee J. Prenatal prediction of neonatal survival in cases diagnosed with congenital diaphragmatic hernia using abdomen-to-thorax ratio determined by ultrasonography. J Obstet Gynaecol Res 2014;40:2037-43.

18. Kim H, Sung SC, Kim SH, et al. Early and late outcomes of tota repair of tetralogy of Fallot: risk factors for late right ventricular dilatation. Interact Cardiovasc Thorac Surg 2013;17:956-62.

19. Park CS, Lee JR, Lim HG, et al. The long-term result of total repair for tetralogy of Fallot. Eur J Cardiothorac Surg 2010;38:311-7.

20. De Wals P, Tairou F, Van Allen MI, et al. Reduction in neural-tube defects after folic acid fortification in Canada. N Engl J Med 2007;357:135-42.

21. Khoshnood $B$, Loane $\mathrm{M}$, de Walle $\mathrm{H}$, et al. Long term trends in prevalence of neural tube defects in Europe: population based study. BMJ 2015;351:h5949.

22. De-Regil LM, Peña-Rosas JP, Fernández-Gaxiola AC, et al. Effects and safety of periconceptional oral folate supplementation for preventing birth defects. Cochrane Database Syst Rev 2015:CD007950.

23. Ganchimeg T, Ota E, Morisaki N, et al. Pregnancy and childbirth outcomes among adolescent mothers: a World Health Organization multicountry study. BJOG 2014;121(Suppl 1):40-8. 
24. Vu LT, Nobuhara KK, Laurent C, et al. Increasing prevalence of gastroschisis: population-based study in California. J Pediatr 2008;152:807-11.

25. Kirby RS, Marshall J, Tanner JP, et al. Prevalence and correlates of gastroschisis in 15 states, 1995 to 2005. Obstet Gynecol 2013;122:275-81.

26. Park SY, Jang IA, Lee MA, et al. Screening for chromosomal abnormalities using combined test in the first trimester of pregnancy. Obstet Gynecol Sci 2016;59:357-66.

27. Cocchi G, Gualdi S, Bower C, et al. International trends of Down syndrome 1993-2004: births in relation to maternal age and terminations of pregnancies. Birth Defects Res A Clin Mol Teratol 2010;88:474-9.

28. Canfield MA, Honein MA, Yuskiv N, et al. National estimates and race/ethnic-specific variation of selected birth defects in the United States, 1999-2001. Birth Defects Res A Clin Mol Teratol 2006;76:747-56.

29. Park JH, Na J-Y, Lee BW, et al. A statistical analysis on forensic autopsies performed in Korea in 2015. Korean Journal of Legal Medicine 2016;40:104-18.

30. Hoyert DL. The changing profile of autopsied deaths in the United States, 1972-2007. NCHS Data Brief 2011;67:1-8. 